Vol. 12(5), pp. 52-59, 16 March, 2017

DOI: $10.5897 /$ J PS2016.4592

Artic le Number: 060876B63495

ISSN 1992 - 1950

Copyright @2017

\title{
Pressure and temperature effects on corona onset voltage in electrostatic precipitators
}

\author{
Fadhil Khaddam Fuliful \\ Physics Department, College of Science, Karbala University, Karbala, Iraq. \\ Received 16 December, 2016; Accepted 8 March, 2017
}

\begin{abstract}
Corona onset voltage is one of the most important factors that determine the charging toxic particle in an industrial application. Electrostatic precipitators (ESP) remove the suspended particle with a gas inlet. This paper developed Peek's formula to estimate the maximum electric field near the discharge wire in corona discharge models, the values of maximum electric field and corona onset voltage near the discharge wires have been calculated for different values of pressure and temperature for confined gas in a region between the electrodes in ESP. The model uses finite difference method (FDM) to solve governing equations (Poisson's and current continuity equations) simultaneously. Computer simulation method uses FORTRAN program to estimate potential distribution and maximum electric field intensity. The calculated corona onset voltage values are compared with the calculated values of different models.
\end{abstract}

Key words: Corona onset voltage, corona discharge, electric field distribution, electrostatic precipitators.

\section{INTRODUCTION}

As far as the design of high voltage apparatus is concerned, the knowledge of the corona onset voltage, which is a fundamental aspect always challenges design engineers. Lately, this information has gained more importance in compact transmission line designs where the average E-field magnitude is naturally higher as compared to conventional structures (Olsen et al.,1997).

The globalization of the environmental pollution problems caused by the increase of industrial production will lead to the cleaning of the waste gases. The basic idea of electrostatic precipitators is charging the toxic particles such as $\mathrm{CO}_{2}$, Nox by interring it. Electrostatic field drives the charged particles to collection on plates connected to earth. The dry plate-type (ESP) is used widely in industrial applications to control dust pollution (Nicolae et al., 2008). It is a new method used to calculate onset voltages in case of negative and positive corona, this method is based on considering electric field and pressure in adjacent surface of conductors. This algorithm is simulated for different pressure and radius of conductors. The configuration of conductors considered is stranded as overhead high transmission lines (Zangeneh and Gholami, 2005). The impact of various variables on corona power losses and corona onset

E-mail: Fadhil.Khaddam@yahoo.com.

Author(s) agree that this artic le remain pemanently open access under the terms of the Creative Commons Attribution License 4.0 Intemational License 
voltages was determined, and $D C$ and $A C$ tests were performed at Fuat Kulunk high voltage laboratory of Istanbul Technical University (Eroncel et al., 2010). Investigation of corona onset was done, and different factors such as the electric field (E-field) distribution around the electrodes and their surface conditions were taken into account (Souza and Lopes, 2008). The corona inception voltage (CIV) of positive discharges in a typical wirecylinder electrode arrangement in air was studied under high voltage DC application, finite element analysis (FEA) implemented. Numerical analysis was carried out on the electric field intensity along the wire-cylinder gap axis, in order to determine the inception voltage of each air gap and define its dependence on geometrical characteristics of the electrodes (Konstantios et al., 2013). A study on how onset voltage is influenced by the number of discharge wires, the wires radius and the spacing between wires and the collecting plates, the initiation of the corona discharge and electric field calculated using the charge simulation method was done (Ziedan et al., 2010). Theoretical investigation of onset voltage was described for negative corona on stranded conductors, the method of calculation is based on criterion developed for formation of repetitive negative corona (Trichel pulses), an accurate calculation of the electric field satisfied in the vicinity of stranded conductors, and the investigated gap is a three-dimensional field problem, to solve this problem, a new modification of the charge simulation technique is presented (EL-Bahy et al., 2007).

A pressure sensing unit is based on a unique corona discharge setup using symmetrical electrode arrangement with simultaneous positive and negative corona generation. The device generates stable corona discharge and enables reliable air pressure measurement in the range of 80 to $105 \mathrm{kPa}$, tested with five prototypes. Three governing parameters, namely electrode geometry, electrode distance and discharge current, were studied in relation to absolute pressure (Van Thanh et al., 2016a).

A miniaturized device generate ion wind flow with very low net charge. Both positive and negative ions are simultaneously generated from two sharp electrodes placed in parallel, connected to a single battery-operated power source. The two-electrode arrangement is symmetrical, where the electrode creating charged ions of one polarity also serves as the reference electrode to establish the electric field required for ion creation by the opposite electrode, and vice versa (Van Thanh et al., 2016b).

This paper aimed to evaluate the corona onset voltage in ESP depending on developing Peek's formula. A mathematical model employed Finite Difference technique to solve Poisson's and current continuity equations simultaneously also the developed formula for calculating the maximum electric field near the discharge wire. The equations programmed in FORTRAN. Corona onset voltage evaluated for different values of pressure and temperature at dust condition, also the influenced of discharge wires, the wires radius and the spacing between wires and collecting plates on the onset voltage calculated. The computed onset voltage values agreed reasonably with those measured experimentally

\section{CORONA ONSET MODELS}

Monitoring the temperature of the gas stream provides useful information on the performance in the ESP and gives useful ideas for diagnosing (maintenance and process operating conditions). The effect of temperature is most important as it relates to the resistivity of the particulate and is an indicator or excessive in leakage into the gas stream. Temperature can also have effects on gas properties such as the relative levels of current, the density and viscosity of the gas stream, as consequence of the particle migration parameters of charge particle also affected. There are several parameters that affect corona onset voltage in addition to the surface E-field, such as the ambient conditions, temperature, air pressure and relative atmospheric conditions. Prediction models of corona onset voltage were few (Olsen et al., 1997; Zangeneh and Gholami, 2005; Eroncel et al., 2010; Konstantios et al., 2013; Ziedan et al., 2010; EL-Bahy et al., 2007; Van Thanh et al., 2016c). Figure 1 shows the regions of corona discharge, the electric field intensity is high in glow region and decreases slowly towards the drift region and equal to zero in passive electrode.

In this paper, an iterative procedure was used to calculate maximum electric field intensity near the corona discharge wire. The model based on FDM was used in solving Poisson's and current continuity equations simultaneously after computing the initial electric field intensity due to the developed Peek's formula. FORTRAN programs are used for investigating electric field distributions along the gap distance (distance between discharge wire and ground plates for ESP), and corona onset voltage near the discharge wire. The boundary conditions needed for the solution of problem domain are value of applied voltage on the discharge wire (equal to the applied DC voltage), the zero potential on the collecting plate, the corona onset gradient on the discharge wire, $E_{c}$ as given by Peek's formula and the estimations of potential distribution at all grid points for the problem domain evaluated due to Cooperman's equation.

If the wires are rough, marred, or specked with dust, as it commonly the case in practice, it is necessary to introduce the roughness factor (f) less than 1 and the values ranged from 0.5 to 0.7 (James et al., 1995).

\section{PEEK'S FORMULA}

The empirical expression developed by Peek in 1929, for the critical 


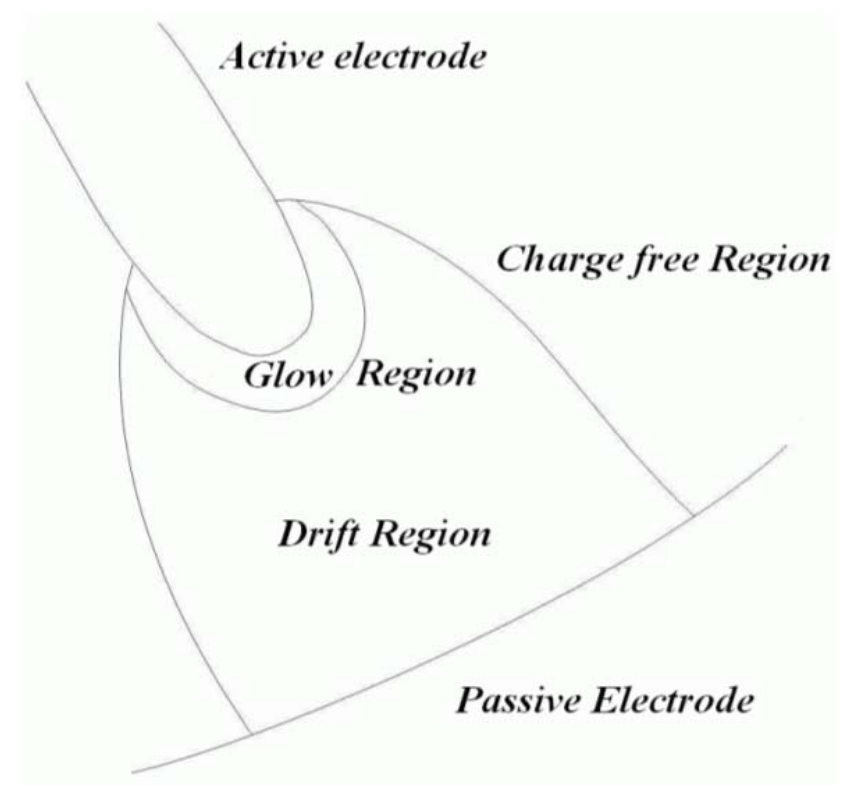

Figure 1. Schematic representation of the regions in corona discharge (Goldman et al., 1982).

E-field is the most widespread and widely used for various arrangements, although originally developed for concentric cylinder arrangements (Kuffel et al., 2000). Equation 1 shows Peek's formula to estimate corona onset as perceived by visual observations.

$E_{c}=31 . \delta \cdot f\left(1+0.308 \cdot(\delta . r)^{-0.5}\right)$

Where $E_{c}=$ critical E-field, $\delta=$ relative air density, $r=$ conductor radius and $f=$ roughness factor. ( $f=1$ for polished wires and $\delta=1$ at NTP).

The corona onset voltage $V_{c}$ may be obtained from the Equation below (James et al., 1995):

$V_{c}=r E_{c} \ln \frac{s_{x}}{r}$

Where $S_{x}$ is the distance between discharge wire and collecting plate.

\section{Zaengl and Nyffenegger equation}

Zaengl and Nyffenegger developed an analytical expression, rewriting Peek's formula in the form presented in Equation 3 (Kuffel et al., 2000):

$\left(E_{c} / \delta\right)^{2}-2\left(\frac{E_{c}}{\delta}\right) E_{\circ} \cdot \ln \left(\frac{E_{c}}{\delta . E_{\circ}}\right)-\left(E_{\circ}\right)^{2}=\frac{42}{\delta r}$

This expression was developed due to deviations obtained with Peek's formula for $\delta r>1$.

\section{Field efficiency factor}

Later on, the influence of the gap geometry was expressed in terms of the "field efficiency factor" (FEF), also called "utilization factor" (Kalenderli et al., 2001) or its reciprocal, the "non-uniformity factor" (Qiu, 1986). The field efficiency factor $(\eta)$ is the ratio between the uniform $E$-field for the gap length $\left(E_{\text {mean }}\right)$ and the maximum $E$-field $\left(E_{\max }\right)$ at rod tip as shown in Equation 4.

$\eta=E_{\text {mean }} / E_{\max }$

For simple structures, the maximum field is taken as the electrode surface, for complex electrode arrangement $E_{\max }$ may appear at any point on an electrode. The FEF measures the "degree of nonuniformity" of the arrangement: the closer it is to 1 , the more uniform the field is in the arrangement.

$\eta=\left(0.45 \cdot \frac{d}{r} \cdot \ln \left(6 \cdot \frac{d}{r}\right) / \ln \left(\frac{d}{r}\right)\right)^{-1}$

Using curve-fitting techniques, an expression was suggested for $\eta$ as a function of the ratio between the gap length $(d)$ and electrode radius $(r)$ (Qiu, 1986), this expression is presented in Equation 5. According to this factor $\eta$ and the maximum E-field, the corona onset voltage $\left(V_{c}\right)$ can be calculated due to Equation 6.

$V_{c}=d \cdot E_{\max } \cdot \eta$

Where $d$ is the gap length and $E_{\max }$ the maximum E-field value.

\section{A new prediction model}

Peek's formula does not considered the high Pressure and Temperature conditions because roughness factor value is one for polished wires. Therefor a new method based on considering high pressure and temperature near the surface of discharge wires in ESP investigated. This model simulated for different pressure and temperature values which are affected on density of the gas in the 
Table 1. Simulated corona onset voltage using Peek's formula for different discharge wire and gap distance.

\begin{tabular}{lcc}
\hline Wire radius $(\mathbf{c m})$ & Gap Length $\mathbf{( c m )}$ & corona onset voltages $\mathbf{( k V )}$ \\
\hline \multirow{3}{*}{0.0129} & 3 & 4.188 \\
& 5 & 4.564 \\
& 7 & 4.811 \\
0.0392 & 3 & 7.071 \\
& 5 & 7.859 \\
& 7 & 8.379 \\
0.1879 & 3 & 14.988 \\
& 5 & 17.530 \\
& 7 & 19.204 \\
0.1 & 3 & \\
& & 11.113 \\
& 5 & 12.672 \\
& 7 & 13.697 \\
\hline
\end{tabular}

Table 2. Simulated maximum E-field $(\mathrm{kV} / \mathrm{cm})$ near the discharge wire for different mathematical models.

\begin{tabular}{|c|c|c|c|c|c|c|}
\hline \multirow{2}{*}{$\begin{array}{l}\text { Wire radius } \\
(\mathrm{cm})\end{array}$} & \multirow{2}{*}{$\begin{array}{l}\text { Gap length } \\
\text { (cm) }\end{array}$} & \multicolumn{5}{|c|}{ Maximum E-field $(\mathrm{kV} / \mathrm{cm})$} \\
\hline & & Peek & Zaengl & Y.Qiu & FEM & FDM \\
\hline \multirow{3}{*}{0.0129} & 3 & \multirow{3}{*}{100.1} & \multirow{3}{*}{101.9} & 231.8 & 116.11 & 28.5 \\
\hline & 5 & & & 272.2 & 98.0 & 20.7 \\
\hline & 7 & & & 358.5 & 96.2 & 16.4 \\
\hline \multirow{3}{*}{0.0392} & 3 & \multirow{3}{*}{78.7} & \multirow{3}{*}{73.2} & 129.8 & 58.5 & 32.7 \\
\hline & 5 & & & 141.5 & 54.2 & 24.5 \\
\hline & 7 & & & 154.5 & 50.8 & 19.3 \\
\hline \multirow{3}{*}{0.1879} & 3 & \multirow{3}{*}{52.9} & \multirow{3}{*}{50.1} & 59.2 & 43.9 & 45.6 \\
\hline & 5 & & & 62.9 & 39.9 & 27.7 \\
\hline & 7 & & & 64.5 & 35.2 & 20.8 \\
\hline
\end{tabular}

ESP, the objective of this work to develop the Peek's formula.

$$
E_{c}=31 \cdot \frac{T_{0}}{T} \cdot \frac{P}{P_{0}} \cdot f\left(1+0.308 \cdot\left(\frac{T_{0}}{T} \cdot \frac{P}{P_{0}} \cdot r\right)^{0.5}\right)
$$

Where $T_{0}$ is the absolute temperature of room air or about $293^{\circ} \mathrm{K}$, $P_{0}$ is the normal atmosphere pressure or $760 \mathrm{mmHg}$ and $T$ and $P$ are actual temperature and pressure of gas for which $\delta$ is to be calculated.

\section{RESULTS AND DISCUSSION}

There are several important cases for which corona can occur, corona onset voltage is considered as a starting point for corona and it is difficult to measure these values experimentally, then theoretical study is necessary. A different empirical formula for calculating the voltage gradient are used and determination of corona onset voltage is useful, it is necessary to evaluate its values at ESP under dust loading.

Table 1 show values of corona onset voltage calculated according to Peek's formula at different values of gap distance, it's evident that corona onset voltage affected by discharge wire radius and gap distance, the computation happen under dust free conditions.

Table 2 shows the simulated maximum E-field $(\mathrm{kV} / \mathrm{cm})$ near the discharge wire for different mathematical models, the comparison shows that the simulated results gives agreement with other models in case of high values for wire radius $(r=0.0392 \mathrm{~cm})$, the reduction of maximum 


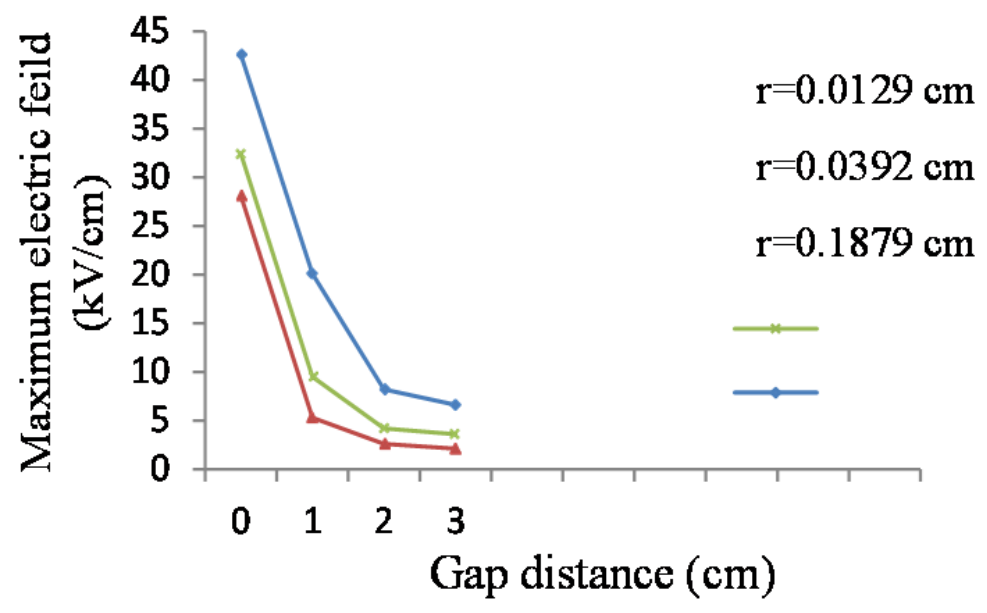

Figure 2. Maximum electric field distribution along the distance between discharges wire and ground plate $(3 \mathrm{~cm})$ for different wire radius.

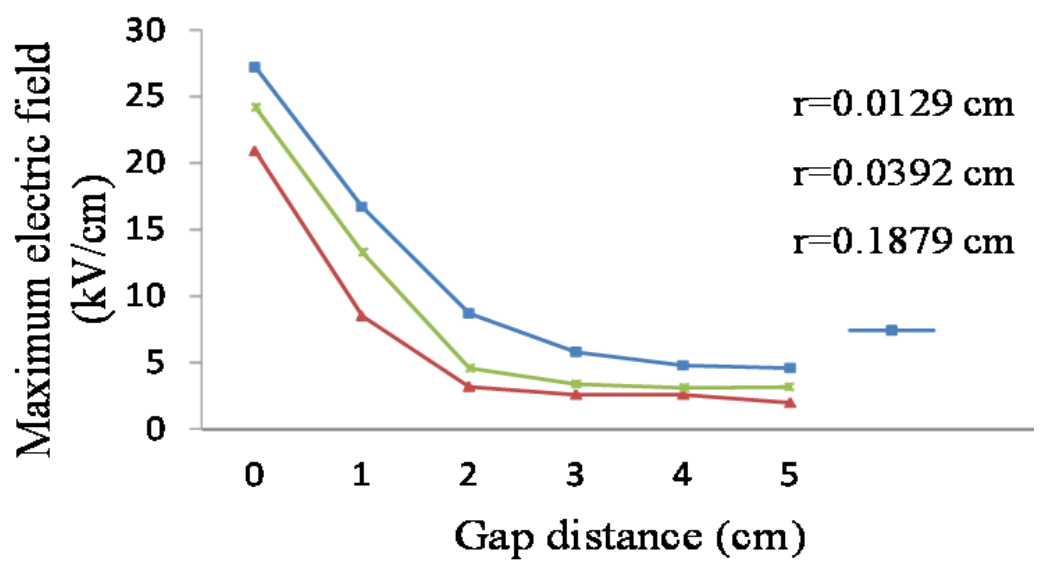

Figure 3. Maximum electric field distribution along the distance between discharges wire and ground plate $(5 \mathrm{~cm})$ for different wire radius.

electric values which are calculated in a new model related to the employed conditions (high pressure and temperature), while the other models used atmospheric conditions.

Figure 2 shows maximum electric field distribution along the gap distance equal to $3 \mathrm{~cm}$ (distance between discharge wire and ground collecting plate), the electric field have highest value near the discharge wire and decreases slowly towards the ground plate, this result investigate the basis of the ionization in corona discharge, the same manner of electric field distribution have been seen in Figures 3 to 4 at the gap distance ( 5 and $7 \mathrm{~cm}$, respectively). The predicted results show that the effects of gap distance on corona onset voltage is weakly as shown in the Figures 2 to 4 , but the effect of wire radius is strongly shown.

Tables 3, 4 and 5 show the effects of high pressure temperature on maximum electric field and corona onset voltage near the corona discharge wire in ESP, it is evident that the increased high pressure-temperature leads to decreases in corona onset voltage and maximum electric field. There are no effects of distance gap on maximum electric field but slightly effect on corona onset voltage but the radius wire still affects them.

\section{Conclusion}

In practice, measuring the corona onset voltage is difficult; therefore, mathematical models are important to evaluate its values. There are different models used for computing corona onset voltage of a gas in atmosphere conditions but dust conditions are poor in the study, the model which has been built in this work is useful for 


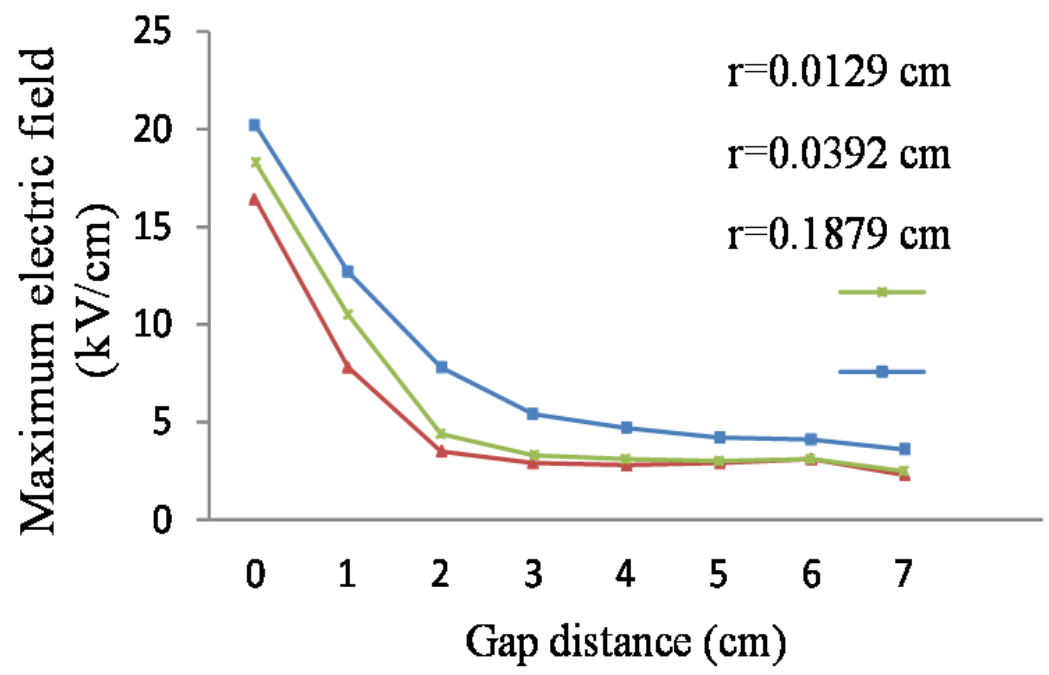

Figure 4. Maximum electric field distribution along the distance between discharges wire and ground plate $(7 \mathrm{~cm})$ for different wire radius.

Table 3. Simulated maximum E-field $(\mathrm{kV} / \mathrm{cm})$ and onset corona voltage $(\mathrm{kV})$ for different values of high pressure-high temperature at wire radius $r=0.0129 \mathrm{~cm}$.

\begin{tabular}{|c|c|c|c|c|c|}
\hline \multirow{2}{*}{ Wire radius $(\mathrm{cm})$} & \multirow{2}{*}{$\begin{array}{l}\text { Gap distance } \\
\text { (cm) }\end{array}$} & \multirow{2}{*}{ Pressure (kPa) } & \multirow[b]{2}{*}{ Temperature (K) } & \multicolumn{2}{|l|}{ FDM } \\
\hline & & & & Maximum electric $(\mathrm{kV} / \mathrm{cm})$ & Onset voltage (kV) \\
\hline \multirow{18}{*}{0.0129} & \multirow{6}{*}{3} & \multirow{18}{*}{500} & 950 & 180 & 6.63 \\
\hline & & & 1050 & 157 & 5.78 \\
\hline & & & 1150 & 139 & 5.10 \\
\hline & & & 1250 & 124 & 4.55 \\
\hline & & & 1350 & 111 & 4.09 \\
\hline & & & 1400 & 106 & 3.90 \\
\hline & & & 950 & 180 & 7.23 \\
\hline & & & 1050 & 157 & 6.30 \\
\hline & & & 1150 & 139 & 5.56 \\
\hline & 5 & & 1250 & 124 & 4.96 \\
\hline & & & 1350 & 111 & 4.46 \\
\hline & & & 1400 & 106 & 4.25 \\
\hline & \multirow{6}{*}{7} & & 950 & 180 & 7.62 \\
\hline & & & 1050 & 157 & 6.64 \\
\hline & & & 1150 & 139 & 5.86 \\
\hline & & & 1250 & 124 & 5.23 \\
\hline & & & 1350 & 111 & 4.71 \\
\hline & & & 1400 & 106 & 4.48 \\
\hline
\end{tabular}

determining corona onset voltage for industrial ESP. Corona onset voltage is low in high pressuretemperature.

\section{CONFLICT OF INTERESTS}

The author has not declared any conflict of interests. 
Table 4. Simulated maximum E-field $(\mathrm{kV} / \mathrm{cm})$ and onset corona voltage $(\mathrm{kV})$ for different values of High Pressure-High temperature at wire radius $r=0.0392 \mathrm{~cm}$.

\begin{tabular}{|c|c|c|c|c|c|}
\hline \multirow{2}{*}{ Wire radius $(\mathrm{cm})$} & \multirow{2}{*}{$\begin{array}{c}\text { Gap distance } \\
(\mathbf{c m})\end{array}$} & \multirow{2}{*}{ Pressure $(\mathrm{kPa})$} & \multirow{2}{*}{$\begin{array}{c}\text { Temperature } \\
\text { (K) }\end{array}$} & \multicolumn{2}{|r|}{ FDM } \\
\hline & & & & Maximum Electric $(\mathrm{kV} / \mathrm{cm})$ & Onset voltage (kV) \\
\hline \multirow{18}{*}{0.0392} & \multirow{6}{*}{3} & \multirow{18}{*}{500} & 950 & 122 & 10.90 \\
\hline & & & 1050 & 107 & 9.62 \\
\hline & & & 1150 & 95.17 & 8.54 \\
\hline & & & 1250 & 85.34 & 7.65 \\
\hline & & & 1350 & 77.19 & 6.92 \\
\hline & & & 1400 & 73.63 & 6.60 \\
\hline & & & 950 & 122 & 12.20 \\
\hline & & & 1050 & 107 & 10.69 \\
\hline & & & 1150 & 95.17 & 9.49 \\
\hline & 5 & & 1250 & 85.34 & 8.51 \\
\hline & & & 1350 & 77.19 & 7.70 \\
\hline & & & 1400 & 73.63 & 7.34 \\
\hline & \multirow{6}{*}{7} & & 950 & 122 & 13.01 \\
\hline & & & 1050 & 107 & 11.40 \\
\hline & & & 1150 & 95.17 & 10.12 \\
\hline & & & 1250 & 85.34 & 9.07 \\
\hline & & & 1350 & 77.19 & 8.21 \\
\hline & & & 1400 & 73.63 & 7.83 \\
\hline
\end{tabular}

Table 5. Simulated maximum E-field $(\mathrm{kV} / \mathrm{cm})$ and onset corona voltage $(\mathrm{kV})$ for different values of high pressure-high temperature at wire radius $r=0.1879 \mathrm{~cm}$.

\begin{tabular}{|c|c|c|c|c|c|}
\hline \multirow{2}{*}{ Wire radius $(\mathrm{cm})$} & \multirow{2}{*}{$\begin{array}{c}\text { Gap distance } \\
\text { (cm) }\end{array}$} & \multirow{2}{*}{ Pressure $(\mathrm{kPa})$} & \multirow{2}{*}{$\begin{array}{c}\text { Temperature } \\
\text { (K) }\end{array}$} & \multirow{2}{*}{ Maximum Electric (kV/cm) } & \multirow[b]{2}{*}{ Onset voltage (kV) } \\
\hline & & & & & \\
\hline \multirow{18}{*}{0.1879} & \multirow{6}{*}{3} & \multirow{18}{*}{500} & 950 & 79.65 & Onset voltage kV \\
\hline & & & 1050 & 70.48 & 22.54 \\
\hline & & & 1150 & 63.09 & 19.94 \\
\hline & & & 1250 & 57.03 & 17.85 \\
\hline & & & 1350 & 51.97 & 16.14 \\
\hline & & & 1400 & 49.75 & 14.70 \\
\hline & & & 950 & 79.65 & 14.07 \\
\hline & & & 1050 & 70.48 & 26.34 \\
\hline & & & 1150 & 63.09 & 23.32 \\
\hline & 5 & & 1250 & 57.03 & 20.88 \\
\hline & & & 1350 & 51.97 & 18.87 \\
\hline & & & 1400 & 49.75 & 17.20 \\
\hline & \multirow{6}{*}{7} & & 950 & 70.65 & 16.46 \\
\hline & & & 1050 & 70.48 & 28.88 \\
\hline & & & 1150 & 63.09 & 25.55 \\
\hline & & & 1250 & 57.03 & 22.87 \\
\hline & & & 1350 & 51.97 & 20.68 \\
\hline & & & 1400 & 49.75 & 18.84 \\
\hline
\end{tabular}




\section{REFERENCES}

EL-Bahy MM, Abouelsaad M, Abdel-Gawad N, Badawi M (2007). Onset voltage of negative corona on stranded conductors. J. Phys. D: Appl. Phys. 40:1-8.

Eroncel C, Ilhan S, Ozdemir A, Kaypmaz A (2010). Corona Onset Voltage and Corona Power Losses in an Indoor Corona Cage, Proceedings of the 14th International Middle East Power Systems Conference (MEPCON'10), Cairo University, Egypt, December 1921, 2010, Paper ID 286.

Goldman M, Sigmond RS, Nicole R (1982). Corona and Insulation. IEEE Trans. Electr. Insul. El-17(2).

James HT, Phil AL, Toshiaki Y, David WC (1995). Electrostatic Precipitators, Research Triangle Institute 1995.

Kalenderli Ö, Önal E, Altay Ö (2001). Computing the Corona Onset and the Utilization Factor of Rod-Plane Electrode by Using Charge Simulation Method. Electrical Insulation Conference and Electrical Coil \&Winding Conference, October 2001. Manufacturing.

Konstantios NK, Antonios XM, Emmanouil DF (2013).Finite element analysis method for detection of the corona discharge inception voltage in a wire-cylinder arrangement. Recent Advances in Finite Differences and Applied \& Computational Mathematics, Mathematics and Computers in Science and Engineering Series, 12:188-193.

Kuffel E, Zaengl WS, Kuffel J (2000). High Voltage Engineering Fundamentals. Second Edition, 2000.

Nicolae PG, Vaida V, lagar A, Dinis CM (2008). Improvement of Technological and Electric Performances for Plate Type Electrostatic Precipitators with Three Sections. Wseas Trans. Power Syst. 3(8).

Olsen RG, Phillips DB, Pedrow PD (1997). Extrapolation of a corona Streamer1 Onset criterion to general convex conductor surface" $10^{\text {th }}$ International on High Voltage Engineering, August 1997.

Qiu Y (1986). Simple Expression of Field Non uniformity Factor for Hemispheric ally Capped Rod-Plane Gaps. IEEE Trans. Electr. Insul. El-21(4).

Souza AL, Lopes IJS (2008). Corona Onset Models: A Computational and Experimental Evaluation. In Electrical Insulation and Dielectric Phenomena, 2008. CEIDP 2008. Annual Report Conference on (pp. 698-701).
Van Thanh D, Bui TX, Tran TT, Phan CD, Terebessy HT (2016c). Corona Based Air-Flow Using Parallel Discharge Electrodes. Exp. Therm. Fluid Sci. 79:52-56.

Van Thanh D, Thien XD, Tibor T, Tung TB (2016b). Bipolar corona discharge based air flow generation with low net charge. Sens. Actuators A. 244:146-155.

Van Thanh D, Tung TB, Thien XD, Tibor T (2016a). Pressure sensor based on bipolar discharge corona configuration. Sens. Actuators $A$ 237:81-90.

Zangeneh A, Gholami A (2005). A New Method for Calculation of Corona Inception Voltage in Stranded Conductors of Overhead Transmission Lines, ${ }^{20}$ th International Power System Conference, 2005.

Ziedan H, Sayed A, Mizuno A, Ahmed A (2010). Onset Voltage of Corona Discharge in Wire-Duct Electrostatic Precipitators. Int. J. Plasma Environ. Sci. Technol. 4(1). 